\title{
Protecting the environment and rationalizing energy sources for future generations
}

\section{BULQUEES ISMAIL DAGHITSTANI}

\author{
Article Chronicle: \\ Received : \\ 30.10.2017; \\ Revised : \\ 16.11.2017; \\ Accepted : \\ 26.11.2017
}

\section{Key Words :}

Environmental pollution, Child awareness, Environmental education

\begin{abstract}
The research aims at revealing the current state of the environment and energy sources for early childhood and how the child contributes to rationalization for future generations in Saudi Arabia. The research used the descriptive approach on a sample of mothers of children and kindergarten teachers. A randomized stratified sample of the study population (669) was selected as follows: Mothers: 83, Kindergarten Teachers: 586. This sample was distributed to the diverse regions of the Kingdom to be representative of the original community of the study. The questionnaire was used as a tool to identify the views of the sample of the study. The tool was presented to a number of arbitrators to get rid of some of the paragraphs that are not related to the subject and were rephrased in their final form to be composed of 30 words divided into three axes with a reality of 10 per axis. The results of the study showed that there is a great consensus of more than 80 per cent among the respondents about the terms of the questionnaire, which is considered an important result of the study or the study revealed the existence of some activities and activities that aim to awareness of the child and his participation in energy conservation and protection of the environment, On the one hand, the child needs regular environmental education and not just activities and activities.

HOW TO CITE THIS ARTICLE : Daghitstani, Bulquees Ismail (2017). Protecting the environment and rationalizing energy sources for future generations. Asian J. Environ. Sci., 12(2): 114-128, DOI: 10.15740/HAS/AJES/12.2/ 114-128.
\end{abstract}

Author for correspondence : BULQUEES ISMAIL DAGHITSTANI

Education College-King Saud University, RIYADH SAUDI ARABIA 